\title{
Dyadic Adjustment, Family Coping, Body Image, Quality of Life and Psychological Morbidity in Patients with Psoriasis and Their Partners
}

\author{
M. Graça Pereira • Laura Brito • Tom Smith
}

(C) International Society of Behavioral Medicine 2011

\begin{abstract}
Background Psoriasis is an incurable and chronic disease that includes unpredictable periods of remission and relapse requiring long-term therapy.

Purpose This paper focuses on the relationship among family coping, psychological morbidity, body image, dyadic adjustment and quality of life in psoriatic patients and their partners.

Method One hundred and one patients with psoriasis and 78 partners comprised the sample. They were regular users of the Dermatology Service of a Central Northern hospital in Portugal and a private dermatology clinic. Patients with psoriasis were assessed on anxiety, depression, body image, quality of life, dyadic adjustment and family coping. Partners were assessed on the same measures except body image and quality of life.

Results A positive relationship among dyadic adjustment, psychological morbidity and family coping in patients and their partners was found. Also, patients with lower levels of quality of life had partners with higher levels of depressive and anxious symptoms. Better dyadic adjustment predicted family coping in the psoriatic patient. High levels of dyadic
\end{abstract}

M. G. Pereira $\cdot$ L. Brito

University of Minho,

Braga, Portugal

T. Smith

Florida State University,

Tallahassee, FL, USA

M. G. Pereira $(\bowtie)$

Escola de Psicologia, Universidade do Minho,

Campus de Gualtar,

4710-057 Braga, Portugal

e-mail: gracep@psi.uminho.pt adjustment in patients and low partners' trait anxiety predicted better dyadic adjustment in partners.

Conclusion The results highlight the importance of incorporating family variables in psychological interventions in psoriasis' care, particularly family coping and dyadic adjustment as well as the need for psychological intervention to focus both on patients and partners.

Keywords Psoriasis $\cdot$ Patients $\cdot$ Partners

\section{Introduction}

Psoriasis is an incurable and chronic disease that affects approximately $2 \%$ of the world's population. The disease includes unpredictable periods of remission and relapse requiring long-term therapy and can develop at any age [1]. In the Iberian Peninsula, it is more prevalent in men and begins before age 30 in $65 \%$ of the cases [2].

The pathophysiology of psoriasis is complex, involving components of the innate and adaptive immune systems, genetics and environment (stress, skin injury, medication, climate, alcohol and infection). This interplay of factors results in an increase in antigen presentation and the activation of $\mathrm{T}$ helper cell type 1 and $\mathrm{T}$ helper cell type 17 , responsible for cutaneous plaques of psoriasis [3, 4].

Zachariae and colleagues [5] reported that patients with psoriasis have $40-90 \%$ more psychological morbidity than the general population. Several studies have shown that $40 \%$ of the psoriatic patients present with high levels of anxiety [6], 10\% present with clinical levels of depression [7], 38\% present with pathological levels of worrying [8] and $10 \%$ present with suicidal ideation [9].

Ginsburg and Link [10] suggested that older age at onset of psoriasis and gender (male) were associated with 
lower psychosocial morbidity. Patients who were older at the time of onset of their psoriasis reported being less sensitive to others' opinions, had a lesser tendency to anticipate rejection in social situations, were less secretive and had fewer feelings of guilt and shame in relationship to their psoriasis. Sampogna et al. [11] found the prevalence of psychiatric morbidity to be higher in women than men. Kossakowska et al. [12] found gender and age onset to be the main contributors to negative emotional control. In fact, adjusting to psoriasis later in life may be more difficult than in earlier years when a patient is young and has a lot of time to deal with negative emotions, especially anger. However, Gupta et al. [13] found patients with early onset (younger than 40 years) presenting with greater psychopathology, probably as a result of greater genetic susceptibility and experiencing more severe and recurrent psoriasis.

The burden of psoriasis is substantial, with an impact on quality of life comparable with that observed in major chronic diseases such as cancer, arthritis and depression [14]. Psoriasis negatively impacts physical, emotional, social, sexual, professional and financial well-being [1518]. In fact, psoriasis causes problems in various dimensions of health-related quality of life including daily activities, leisure, work/school and personal relationships [19]. Psoriatic patients' quality of life was found to be influenced more by the experienced stigma than the severity of the disorder.

Krueger and colleagues [20] suggested that the severity of psoriasis is mainly a quality of life issue. The two main contributors to stress in patients with psoriasis are engaging in avoidance behaviour and the belief that others evaluate them on the basis of their skin disease. However, there is no significant relationship between either physical severity or anatomic location of psoriasis and psychological disability. Therefore, severity of psoriasis is a composite of physical and psychological factors [6].

Stigmatization is a central experience of psoriasis that has a broad psychic and social impact. As might be expected, patients with skin disorders may experience social rejection, avoiding touch and fearing contagion or filth. Such experiences devastate patients' quality of life [21] and are associated with significant levels of social embarrassment, life disruption and social withdrawal [22]. In fact, distorted body image in psoriasis is associated with problems in self-perception as a desirable sexual being and disrupted intimate relationships [23].

Dyadic adjustment is also affected in psoriatic patients. Frangos and Kimball [24] found the rate of divorce in patients with psoriasis to be $11 \%$ and the negative impact on relationships to be similar to that of other chronic conditions. Koo [25] also found psoriasis to be a major obstacle in creating and sustaining intimate relationships. Depression, anxiety, coping and acrimonious disputes mediate the impact of psoriasis on dyadic adjustment [26]. Richards et al. [27] studied the psychological impact of psoriasis in healthy partners and found significant correlations between patient and partner levels of anxiety and depression. Gupta and Gupta [28] found that $40 \%$ of psoriatic patients experience a decrease in initiating or being receptive to sexual intimacy or report having sexual problems related to their psoriasis [29].

Just as negative interactions may adversely affect marital well-being, positive interactions between the patient and his/ her partner significantly improve coping strategies aimed at outbreaks of psoriasis [30, 31]. Partners who show unconditional acceptance, demonstrate respect and sensitivity, use humour and help the patient feel valued and attractive have an ameliorating effect on marital well-being [32].

In Portugal, there are no studies on psoriatic patients and their partners. In order to guide interventions that promote quality of life and facilitate a better understanding of couples' coping strategies, this study focuses on the key variables associated with outbreaks of psoriasis. In this paper, five research questions were examined: First, how are dyadic adjustment, psychological morbidity and family coping in patients related to the same variables in their partners? Second, what are the correlations between quality of life in patients and psychological morbidity in their partners? Third, what are the predictors of family coping in patients? Fourth, what are the predictors of dyadic adjustment in partners? Finally, what is the influence of age onset and perception of illness severity on patient's psychological variables?

Based on the literature, the authors expected to find a positive relationship between patients and partners' variables and a negative relationship between quality of life in patients and psychological morbidity in partners. The authors also expected severity of psoriasis, psychological morbidity, body image and dyadic adjustment to predict family coping in patients. Finally, it is expected that psychological morbidity and body image in patients negatively predict dyadic adjustment in partners.

\section{Method}

Procedure

The sample consisted of all psoriatic patients seen by four physicians who practiced in two locations (i.e. Dermatology Service of a Central Northern Hospital and an associated private clinic) over a 2 -year period. These physicians were responsible for all psoriatic patients seen in the hospital and clinic. Patients were invited by their physicians to participate. Patients were free to decline participation and only those who showed 
an interest were contacted by the researcher. In order to participate, all patients and partners completed consent forms that outlined the study procedures.

After receiving the list of prospective patients, a research assistant contacted their partners and explained the study. Partners were instructed to come to the next regularly scheduled patient appointment. Initially, 120 patients and partners were contacted but only 101 patients and 78 partners filled out the consent forms.

Patients and their partners completed questionnaires in separate rooms. Not all patients had partners, therefore there is a significant difference in the number of partners and patients. In addition, partners with psoriasis were excluded from the study.

\section{Sample Characteristics}

The psoriatic patient sample $(n=101)$ was equally split between men and women (50.5\% male and $49.5 \%$ female). Similarly, partners $(n=78)$ were also equally split $(47.4 \%$ male and $52.6 \%$ female). Mean age was for patients 43.9 years $($ s.d. $=14.3)$ and 45.7 years $($ s.d. $=14.15)$ for partners. Nearly half of patients (45.5\%) finished the sixth grade, $17 \%$ finished the ninth grade, $19.5 \%$ completed secondary education and, finally, $18 \%$ finished college. Partners had roughly the same distribution: $50 \%$ had 4-6 years of education, $24.4 \%$ had between a seventhand ninth-grade education, and finally, $10 \%$ finished graduate school. On average, patients were diagnosed with psoriasis at age 24 (s.d.=12.6). Age of onset was grouped according to following ranges: before age 15 (22.8\%), between 16 and 30 years old (49.5\%) and above 31 years old (27.7\%). Severity of psoriasis was categorized, according to patients and partners' perception, as mild (patients $=16.8 \%$, partners $=12.8 \%$ ), moderate (patients $=50.5 \%$, partners $=$ $57.7 \%)$ and severe (patients $=32.7 \%$, partners $=29.5 \%$ ).

\section{Instruments}

Patients completed the following questionnaires: Hospital Anxiety and Depression Scale (HADS), Body Image Scale (BIS), Psoriasis Disability Index (PDI), Dyadic Adjustment Scale (R-DAS) and Family Crisis-Oriented Personal Evaluation Scale (F-COPES). Instruments for partners were StateTrait Anxiety Inventory (STAI), Beck Depression Inventory (BDI), R-DAS and F-COPES.

All the instruments were adapted to the Portuguese sample. The procedure followed Bradley's orientation [33], which includes translation to Portuguese by a bilingual person, followed by a translation back to English, comparison between the two versions, adaptation of specific terms by a physician, pre-test of the research version to assess comprehension of items in a sample of 12 patients and, finally, elaboration of the Portuguese version. Psychometric properties for all adapted instruments, including Cronbach's alphas, are presented below.

Psoriasis Disability Index PDI measures the quality of life in patients with psoriasis. It was originally described in 1985 [34, 35]. PDI consists of questions related to daily activities, work or school, personal relationships, leisure and treatment. PDI was constructed as a series of 10 questions [34] scored on a visual analogue scale of 1-7, thus producing a score range of 10-70, and was later revised in 1990 with a 15 -question 4-point Likert scale [36]. The scale has a range from 0 to 3 , with items "not at all" scoring " 0 " and "very much" scoring " 3 ". The Portuguese version of the measure has not been normed and has no clinical cut-off scores. PDI total scores range from 0 to 45 with higher scores indicating a greater impairment in a patient's quality of life.

Although a persuasive case can be made for the overall validity of the Portuguese adaptation of the scale, the subscales of the original scale did not hold true. In the exploratory factor analysis, the factors seen in the American instrument were not replicated. To better understand this measure, the authors followed the lead of Kent and Al-Abadie [37], who performed a two-factor solution. The resulting adaptation explained $57 \%$ of the total variance. One factor relates to aspects of everyday activities (items 1, 2, 3, 4, 5 and 15) and the second factor measures relationships with others (items 6 , $7,8,9,10,11,12,13$ and 14). The first factor ("everyday activities") explained $44 \%$ of the total variance while the second factor ("relationship with others") explained $13 \%$ of the total variance. The overall instrument showed high reliability -0.90 - with both factors showing good reliabilities: everyday activities (alpha $=0.83)$ and relationship with others (alpha $=0.90)$ [38]. In this study, psoriatic patients' mean score was 11.12 (s.d.=9.72). Although precise interpretation is not possible, it appears that patients were experiencing a moderate impairment in their quality of life.

Revised Dyadic Adjustment Scale R-DAS is a modification of the original dyadic adjustment scale developed by Spanier [39] and measures the strength of relationships [40]. R-DAS has been shown to distinguish between distressed and nondistressed samples with an overall Cronbach's alpha of 0.90 (total scale) and alphas of 0.81 , 0.85 and 0.80 for consensus, satisfaction and cohesion subscales, respectively [41]. R-DAS is composed of 14 items. In dyadic consensus, the scale ranges from 5 ("always in agreement") to 0 ("always in disagreement"). In dyadic satisfaction, the scale ranges from 0 ("never") to 5 ("always") and the cohesion scale ranges from 0 ("never") to 4 ("every day") in the first item and from 0 ("never") to 5 ("frequent") in the remaining three items. 
Higher scores reflect better perceptions of the quality of the dyadic relationship.

The Portuguese adaptation of R-DAS [42] used 13 items for patients and 14 for partners. For patients, Cronbach's alpha was 0.90 for the overall R-DAS and 0.92 for consensus, 0.87 for satisfaction, and 0.67 for cohesion. For partners, the alpha was 0.90 for the overall R-DAS and 0.92 for consensus, 0.84 for satisfaction, and 0.73 for cohesion. In psoriatic patients, the three factors explained $69.9 \%$ of the variance and $69.5 \%$ in partners. The mean score for psoriatic patients was 48.4 (s.d.=11.5), and the partners' mean was 50.1 (s.d.=12.5).

Body Image Scale The BIS was created in collaboration with the European Organization for Research and Treatment in Cancer and was tested in a heterogeneous sample of 276 British cancer patients [43]. Following revisions, the scale underwent psychometric testing with a sample of 682 patients with breast cancer, using datasets from seven UK treatment trials/clinical studies. The scale showed high reliability: Cronbach's alpha was 0.93 . A factor analysis resulted in a single-factor solution that accounted for more than $50 \%$ of the variability. Higher scores indicate dissatisfaction with body image.

The Portuguese-adapted version [44] for patients with psoriasis showed a reliability of 0.93 . Factor analysis resulted in a single-factor solution accounting for greater than $50 \%$ of the variance. The mean score for psoriatic patients was 10.5 (s.d.=7.8).

State-Trait Anxiety Inventory Form Y STAI measures anxiety in adults [45]. It clearly differentiates between the temporary condition of "state anxiety" and the more general and long-standing quality of "trait anxiety". State anxiety items are $1,2,5,8,10,11,15,16,19$ and 20, and trait anxiety items are 21, 23, 26, 27, 30, 33, 34, 36 and 39 .

The Portuguese-adapted version [46] included 5,000 individuals in a normative sample and found alphas of 0.92 for state anxiety and 0.90 for trait anxiety. In partners, alpha was 0.96 for state anxiety and 0.94 for trait anxiety. Partners' means were 41.81 (s.d. $=14.91$ ) for state anxiety and 40.55 (s.d. $=12.99$ ) for trait anxiety.

Beck Depression Inventory The BDI-II measures depression in adults [46]. The BDI-II is a self-administered 21-item self-report scale measuring symptoms of depression and demonstrates high internal consistency, with alphas of 0.86 and 0.81 for psychiatric and non-psychiatric populations, respectively [47]. For the general population, a score of 21 or over reveals depression. For individuals who have been clinically diagnosed, scores of $0-13$ indicate minimal depression; 14-19, mild depression; 20-28, moderate depression and 29-63, severe depression.
The Portuguese-adapted version has much the same psychometric properties. In partners [48], Cronbach's alpha was 0.89 . The mean score for partners was 8.85 (s.d.=7.62). Unfortunately, no studies to date have established clinical cut-off scores for non-clinical Portuguese samples.

Hospital Anxiety and Depression Scale The HADS measures depression and anxiety in patients [49]. The HADS is a brief, widely used instrument that measures psychological distress. The scale consists of 14 questions - seven for anxiety and seven for depression. Although the questionnaire was designed for hospital outpatients, it has also been extensively used in primary care services. The scale is sensitive to change both during the course of disease and in response to medical and psychological interventions [50]. Scores of 11 or more, on either subscale, are indicative of high psychological morbidity, while scores of 8-10 are considered "borderline" and scores of 0-7 are considered "normal". Cronbach's alpha was 0.93 for the anxiety subscale and 0.90 for the depression subscale.

The Portuguese-adapted version [51] had similar psychometric properties to the original one, with an overall alpha of 0.91 . The Anxiety factor showed an alpha of 0.87 and accounted for $16.3 \%$ of the variance while the depression factor showed an alpha of 0.91 and accounted for $46.2 \%$ of the variance. The mean for psoriatic patients was 7.57 (s.d.=5.63) for depression and 10.36 (s.d.=5.13) for anxiety.

Family Crisis-Oriented Personal Evaluation Scale The FCOPES measures coping strategies in times of stress [52]. The F-COPES assesses behaviour and problem-solving strategies used by families in problematic or difficult situations. This instrument, scored from 1 to 5 , contains 29 coping behaviour items over five subscales: reframing (i.e. positively reframing events to make them more manageable), passive appraisal (i.e. minimization of the response to problematic issues), acquiring social support (i.e. assesses the nuclear family's ability to use help from relatives, friends, neighbours and extended family as resources), seeking spiritual support (i.e. family's ability to use this kind of support as a resource) and mobilising family to acquire and accept help from community resources outside the nuclear/extended family or other relatives). Higher scores represent a family's greater use of the respective strategy.

The Portuguese-adapted version has 29 items showing good reliability [53] with all subscales presenting alphas over 0.70 except passive appraisal which showed an alpha of 0.55 . In psoriatic patients, the alpha for the overall FCOPES was 0.86 and was 0.70 for reframing, 0.52 for passive appraisal, 0.80 for acquiring social support, 0.81 
for seeking spiritual support and 0.75 for mobilising family to acquire and accept help. For partners, the alpha for the overall F-COPES was 0.88 , and was 0.66 for reframing, 0.69 for passive appraisal, 0.83 for acquiring social support, 0.84 for seeking spiritual support and 0.77 for mobilising family to acquire and accept help. Psoriatic patients' mean score was 97.4 (s.d. $=15.97)$ while partners' mean score was 94 (s.d.=17.9).

\section{Data Analysis}

First, Pearson correlations were obtained to identify relationships between family and individual variables. Later, a regression analysis was performed to determine the best predictors of family coping and dyadic adjustment. Since the goal was to assess the contribution of partners' variables on patients and the impact of patients' psychological variables after the contribution of socio-demographic/clinical variables, the stepwise method was selected. The only variables included in the model were those that presented a significant correlation with the dependent variable. A pairwise exclusion was conducted to ensure that there would be an equal number $(n=78)$ for all analyses that included both patients and partners. For analyses that involved just patients, the entire sample of 101 was used.

\section{Results}

Influence of Severity of Psoriasis

Severity of psoriasis was categorized as mild, moderate or severe according to patients' perceptions. Results revealed significant differences in anxiety, $\left(\chi^{2}=7.307 ; p=.026\right)$, quality of life (global and daily activities), $\left(\chi^{2}=9.568 ; p=\right.$ $0.017 ; \chi^{2}=8.171 ; p=0.008$ ) and dyadic adjustment (global and cohesion), $\left(\chi^{2}=6.722 ; p=0.035 ; \chi^{2}=10.30 ; p=0.006\right)$. In fact, psoriatic patients perceiving their illness as severe, presented with more anxiety, worse quality of life (global and daily activities) and lower dyadic adjustment (global and cohesion) when compared with those exhibiting mild or moderate severity (Table 1).

\section{Influence of Age Onset}

Age of onset was grouped according to the following categories: before age 15, between 16 and 30 years old and above 31 years old. Results revealed significant differences in psychological morbidity. Patients whose illness developed between ages 16 and 30 presented with more depressive symptoms $\left(\chi^{2}=7.263 ; p=0.026\right)$ and anxiety $\left(\chi^{2}=8.622 ; p=0.013\right)($ Table 2$)$.
Predictors of Family Coping in Patients

Since sex, age at onset of psoriasis and perception of illness severity were correlated with family coping, they were all introduced in the first block, in the regression analysis. Psychological variables pertaining to the patient that were also correlated with patient's family coping, i.e. body image, psychological morbidity and dyadic adjustment, were introduced in the second block. Although other variables did not prove to be significant, patients' dyadic adjustment explained $13 \%$ of the variance (Table 3 ).

Family Coping, Dyadic Adjustment and Psychological Morbidity in Patients and Partners

Dyadic adjustment was negatively correlated with psychological morbidity and family coping in patients. The same result was found in partners.

Dyadic adjustment and family coping in partners were negatively associated with psychological morbidity in patients. However, family coping in partners was not associated with depression in patients (Table 4).

Quality of Life in Psoriatic Patients Versus Psychological Morbidity in Partners

Results showed a significant correlation between quality of life (global, everyday activities and relationship with others) in patients and psychological morbidity in partners. Patients with low quality of life (globally, on everyday activities and on relationship with others) had partners with higher levels of psychological morbidity (Table 5).

\section{Predictors of Dyadic Adjustment in Partners}

Since the goal was to study the impact of patients' variables on partners' dyadic adjustment, the variables were included in two blocks. In the first block, patients' psychological morbidity, dyadic adjustment and body image were introduced. In the second block, partners' psychological morbidity and family coping were added. Results showed patients' dyadic adjustment and partners' trait anxiety to be significant predictors, explaining $68.5 \%$ of the variance (Table 6).

\section{Discussion}

Psoriatic patients with a severe perception of psoriasis presented with more anxiety, worse quality of life (global and on "everyday activities") and lower dyadic adjustment (global and dyadic cohesion) when compared to patients who perceived themselves as having either mild or 
Table 1 Results of Kruskal-Wallis regarding dyadic adjustment, psychological morbidity, body image, quality of life and family coping in patients according to perception of psoriasis' clinical severity $(N=101)$

\begin{tabular}{|c|c|c|c|c|c|c|}
\hline \multicolumn{2}{|c|}{ Dependent variables } & \multicolumn{3}{|c|}{ Perception of clinical severity (mean rank) } & \multirow[t]{2}{*}{$\chi^{2}$} & \multirow[t]{2}{*}{$p$} \\
\hline & & Mild $(n=17)$ & Moderate $(n=51)$ & Severe $(n=33)$ & & \\
\hline \multirow[t]{2}{*}{ HADS } & Depression & 44.44 & 49.37 & 56.89 & 2.360 & 0.307 \\
\hline & Anxiety & 47 & 45.06 & 62.24 & 7.307 & $0.026^{*}$ \\
\hline BIS & Body image & 45.74 & 47.62 & 58.94 & 3.663 & 0.160 \\
\hline \multirow[t]{3}{*}{ PDI } & Everyday activities & 32.59 & 51.65 & 59.48 & 9.568 & $0.008^{* *}$ \\
\hline & Relationship with others & 38.94 & 51.20 & 56.91 & 4.304 & 0.116 \\
\hline & Global quality of life & 34.29 & 51.23 & 59.26 & 8.171 & $0.017^{*}$ \\
\hline \multirow[t]{4}{*}{ R-DAS } & Consensus & 60.06 & 50.95 & 46.41 & 2.455 & 0.293 \\
\hline & Satisfaction & 58.09 & 48.32 & 51.48 & 1.483 & 0.477 \\
\hline & Cohesion & 69.53 & 50.91 & 41.59 & 10.301 & $0.006^{* *}$ \\
\hline & Global dyadic adjustment & 66.68 & 50.21 & 44.15 & 6.722 & $0.035^{*}$ \\
\hline
\end{tabular}

$* p \leq 0.05 ; * * p \leq 0.01$

moderate severity. Scharloo and colleagues [54] concluded that perceptions of psoriasis as a severe illness were associated with a greater frequency of medical consultations and poorer quality of life in terms of physical health, social functioning and mental health.

Skin plays an important role as an organ of communication throughout life, greatly affecting an individual's body image and self-esteem [55]. It is a truism that adolescents and young adults pride themselves on their appearance and have more social contacts and relationships. This is supported by the finding that patients whose illness developed between age 16 and 30 presented with more depressive symptoms and anxiety compared with other age groups. This finding is in accordance with a study by Youn et al. [56] that revealed psoriasis with an onset prior to age 40 to be associated with more psychological stress compared with later onset. Gupta et al. [13] found similar results.

Patients' dyadic adjustment was the only variable that predicted family coping in patients; interestingly, psychological morbidity and body image did not. This result may be a reflection of the quality of the relationship with the partner. In fact, dyadic adjustment appears crucial among patients with chronic conditions, since illness management is complex and multifaceted. As a result, when the patient has a good dyadic adjustment, the couple may be more motivated to utilize family coping strategies and vice versa. In fact, psychological morbidity and body image may not act as predictors, since psychological morbidity in this sample was only moderate, and the same holds true for dissatisfaction with body image (below average) .

Table 2 Results of Kruskal-Wallis regarding dyadic adjustment, psychological morbidity, body image, quality of life and family coping in patients according to age onset $(N=101)$

\begin{tabular}{|c|c|c|c|c|c|c|}
\hline \multicolumn{2}{|c|}{ Dependent variables } & \multicolumn{3}{|c|}{ Age onset (mean rank) } & \multirow[t]{2}{*}{$\chi^{2}$} & \multirow[t]{2}{*}{$p$} \\
\hline & & $<15$ years $(n=23)$ & $16-30$ years $(n=50)$ & $>31$ years $(n=28)$ & & \\
\hline \multirow[t]{2}{*}{ HADS } & Depression & 38.46 & 57.99 & 48.82 & 7.263 & $0.026^{*}$ \\
\hline & Anxiety & 37.26 & 58.59 & 48.73 & 8.622 & $0.013 *$ \\
\hline BIS & Body image & 46.72 & 57.29 & 43.29 & 4.751 & 0.093 \\
\hline \multirow[t]{3}{*}{ PDI } & Everyday activities & 51.15 & 53.01 & 47.29 & .690 & 0.708 \\
\hline & Relationship with others & 54.89 & 53.72 & 42.95 & 3.008 & 0.222 \\
\hline & Total & 52.50 & 53.21 & 45.82 & 1.223 & 0.543 \\
\hline \multirow[t]{4}{*}{ R-DAS } & Dyadic consensus & 47.93 & 49.30 & 56.55 & 1.438 & 0.487 \\
\hline & Dyadic satisfaction & 50.78 & 50.36 & 52.32 & .085 & 0.958 \\
\hline & Dyadic cohesion & 51.65 & 47.92 & 55.96 & 1.381 & 0.501 \\
\hline & Total & 48.83 & 48.74 & 56.82 & 1.533 & 0.465 \\
\hline
\end{tabular}

${ }^{*} p \leq 0.05$ 
Table 3 Predictors of family coping in patients using a linear regression (stepwise method; $N=78)$

$R^{2}=0.193 ;$ adjusted $R^{2}=0.132$ $* p \leq 0.05$

A negative relationship between dyadic adjustment and psychological morbidity and also between family coping and psychological morbidity, both in patients and partners, was found. These results emphasize how patients and partners are affected by chronic disease [57], and support previous studies of Basra and Finlay [58] and Eghlileb et al. [59].

The positive correlation between patients' and partners' levels of anxiety and depression is intuitively reasonable. Difficulties in body image, shifts in the social network and decreased sexual intimacy as a result of psoriasis can be triggers for chronic stress, threatening patients' and partners' well-being as well as relationships with others [30]. As a result, it is not surprising that partners' dyadic adjustment was negatively associated with psychological morbidity in patients. These findings suggest the importance of couples' relationships to patients' psychological adjustment to medical conditions $[60,61]$.

Anxiety was inversely related to family coping, and dyadic adjustment was positively related to family coping. According to Rosenstrauch [62], these results may be the result of an intentional protective buffering strategy to exclude the partner from worries and concerns. The protective buffering strategy may explain the results regarding anxiety but does not explain the results regarding depression. Not as intuitive, however, was the finding that depression in patients was not correlated with family coping in partners. Perhaps partners expect depression to be part of the patients' condition and therefore are less affected by it. Furthermore, patients were moderately depressed, and perhaps family coping strategies are strongly associated with severe depression. These results are in accordance with Duarte [64], found lupus patients with greater disease activity to present with more anxiety symptoms, higher levels of fatigue, more dissatisfaction with their body image, worse quality of life and less utilization of family coping strategies. Finally, partners' active engagement or coping strategies, including constructive problem solving, were associated with better dyadic adjustment [61-63]. Duarte and Pereira [64] also found better dyadic adjustment (cohesion) to be associated to the use of more family coping strategies, albeit in patients with SLE.

Quality of life in patients and psychological morbidity in partners were inversely associated. Patients with lower levels of quality of life had partners with higher levels of
Table 4 Results of Pearson correlations among dyadic adjustment, psychological morbidity and family coping in patients and partners $(N=78)$

\begin{tabular}{lcccc}
\hline \multirow{2}{*}{ Partners } & \multicolumn{3}{l}{ Psoriatic patients } & \\
\cline { 2 - 5 } & HADS (depression) & HADS (anxiety) & R-DAS & F-COPES \\
\hline BDI & $0.376^{* *}$ & $0.384^{* *}$ & $-0.562^{* * *}$ & $-0.358^{* *}$ \\
& 0.001 & 0.001 & 0.000 & 0.001 \\
STAI (state) & $0.300^{* *}$ & $0.360^{* *}$ & $-0.563^{* * *}$ & $-0.290^{*}$ \\
& 0.008 & 0.001 & 0.000 & 0.010 \\
STAI (trait) & $0.353^{* *}$ & $0.424^{* * *}$ & $-0.587^{* * *}$ & $-0.328^{* *}$ \\
& 0.002 & 0.000 & 0.000 & 0.003 \\
R-DAS & $-0.292^{*}$ & $-0.245^{*}$ & $0.838^{* * *}$ & $0.392^{* * *}$ \\
& 0.010 & 0.031 & 0.000 & 0.000 \\
F-COPES & -0.195 & $-0.248^{*}$ & $0.438^{* * *}$ & $0.434^{* * *}$ \\
& 0.086 & 0.029 & 0.000 & 0.000 \\
\hline
\end{tabular}


Table 5 Results of Pearson correlations between quality of life in patients and psychological morbidity in partners $(N=78)$

\begin{tabular}{llll}
\hline & \multicolumn{3}{l}{ Patients } \\
\cline { 2 - 4 } Partners & $\begin{array}{l}\text { PDI everyday } \\
\text { activities }\end{array}$ & $\begin{array}{l}\text { PDI relationship } \\
\text { with others }\end{array}$ & $\begin{array}{l}\text { Global } \\
\text { PDI }\end{array}$ \\
\hline BDI & $0.256^{*}$ & $0.236^{*}$ & $0.290^{* *}$ \\
STAI (state) & 0.024 & 0.038 & 0.010 \\
& $0.224^{*}$ & $0.258^{*}$ & $0.291^{* *}$ \\
STAI (trait) & 0.048 & 0.023 & 0.010 \\
& $0.281^{*}$ & $0.272^{*}$ & $0.329^{* *}$ \\
& 0.013 & 0.016 & 0.003 \\
\hline
\end{tabular}

${ }^{*} p \leq 0.05 ;{ }^{*} p \leq 0.01$

depression and anxiety. This was especially true regarding the two dimensions "relationship with others" and "everyday activities". These results show how the burden of psoriasis may extend far beyond the physical symptoms experienced by the patient. Psoriasis influences many different spheres of a patient's life, and consequently, the effects on a patient's social and mental health may be dramatic. As a result, routine activities and social contacts may often be compromised, increasing partners' morbidity. Therefore, quality of life of partners and relatives of psoriatic patients may be significantly affected [59]. Another explanation for these results may have to do with caregiver burden that may mediate the relationship between psychological morbidity and quality of life [66]. Future research should analyse this hypothesis and assess other stressors in the couple's life that may be responsible for the exacerbation of clinical conditions in patients that impact partners' morbidity as well.

As stated earlier, partners who show unconditional acceptance, demonstrate respect and sensitivity and make their partner feel valued and attractive have a powerful effect on patients' dyadic adjustment [32]. Not surprisingly, patients' dyadic adjustment predicted partners' dyadic adjustment. Such results may be due to a re-evaluation and a change of perspective on what is important, like placing less emphasis on appearance [67]. In fact, it is important that patients accept their skin's appearance with the accompanying scaliness, the localization of the injuries or pain in order to increase sexual intimacy, decrease emotional tension and raise dyadic adjustment $[23,29]$. As a result, it comes as no surprise that dyadic adjustment predicts family coping in patients. Thus, to prevent the typical feelings of frustration, anger and irritation [23], a dramatic evaluation of body image may be necessary. Rolland [31] observed that a communication style characterized by acceptance is essential during a time when partners provide a basic and, perhaps, the only source of interpersonal support. The onset of psoriasis presents a challenge for couples to reorganize and fundamentally change the nature of their relationship [30]. Finally, partners' trait anxiety also predicted dyadic adjustment in partners. This finding is in accordance with previous studies that found anxiety to be negatively correlated with dyadic adjustment $[68,69]$.

\section{Conclusion}

The results of this study highlight the importance of incorporating family variables in psychosocial interventions for psoriatic patients. According to the results, interventions must focus on the dramatic shift in the couple's relationship, which may entail new roles and demands. This study provides evidence that psychosocial interventions should focus both on patients and the family system. Because partners' morbidity is associated with levels of patients' morbidity and quality of life, in order to increase both patient and partner quality of life, couples' counselling and therapy appear to be key components of any holistic
Table 6 Predictors of dyadic adjustment in partners using a linear regression (stepwise method; $N=78$ )

\begin{tabular}{|c|c|c|c|c|c|c|}
\hline & & \multirow[b]{2}{*}{ Variables } & \multicolumn{2}{|c|}{ Patient variables } & \multicolumn{2}{|c|}{ Partner variables } \\
\hline & & & $\beta$ & $p$ & $\beta$ & $p$ \\
\hline \multirow[t]{4}{*}{1} & Patients & Depression (HADS) & 0.004 & 0.960 & 0.009 & 0.914 \\
\hline & & Anxiety (HADS) & 0.017 & 0.858 & 0.087 & 0.357 \\
\hline & & Body image (BIS) & -0.005 & 0.964 & 0.014 & 0.880 \\
\hline & & Dyadic adjustment (R-DAS) & 0.792 & $0.000 * *$ & 0.651 & $0.000 * *$ \\
\hline \multirow[t]{5}{*}{2} & Partners & Depression (BDI) & & & 0.070 & 0.558 \\
\hline & & Anxiety (state) (STAI) & & & 0.088 & 0.574 \\
\hline & & Anxiety (trait) (STAI) & & & -0.373 & $0.037^{*}$ \\
\hline & & Family coping (F-COPES) & & & 0.150 & 0.053 \\
\hline & & $R^{2}$ change & 2.944 & & 3.684 & \\
\hline
\end{tabular}


medical care in psoriasis [70]. Past standards of care only emphasized psoriatic patients and not their partners, and according to results, there should be an expanded standard of care in psoriasis among care providers.

Future studies should address the impact of psoriasis on the couple's developmental phase, patients' and partners' illness representations, caregiver burden and how all these variables are related to dyadic adjustment and quality of life in both patients and partners. Finally, research should also explore the impact of sexual intimacy on patients' and partners' coping strategies [71].

\section{References}

1. Saraceno R, Griffiths CEM. A European perspective on the challenges of managing psoriasis. J Am Acad Dermatol. 2006;54:S81-4.

2. Cabral MF, Baptista A, Cabrita J, Caetano M, Cardoso R, Cirne de Castro JL, et al. Avaliação Epidemiológica da psoríase moderada a grave em Portugal e Espanha. Psoríase Newsletter 2005; 2.

3. Griffiths CE, Barker JN. Pathogenesis and clinical features of psoriasis. Lancet. 2007;370:263-71.

4. Lowes MA, Kikuchi T, Fuentes-Duculan J, Cardinale I, Zaba LC, Haider AS, et al. Psoriasis vulgaris lesions contain discrete populations of Th1 and Th17 T cells. J Invest Dermatol. 2008;128:1207-11.

5. Zachariae R, Zachariae H, Blomqvist K, Davidsson S, Molin L, Mork C, et al. Quality of life in 6497 Nordic patients with psoriasis. Br J Dermatol. 2002;146(6):1006-16.

6. Richards HL, Fortune DG, Griffiths CE, Main CJ. The contribution of perceptions of stigmatisation to disability in patients with psoriasis. J Psychosom Res. 2001;50(1):11-5.

7. Gupta MA, Gupta AK, Schork NJ, Ellis CN. Depression modulates pruritus perception: a study of pruritus in psoriasis, atopic dermatitis and chronic idiopathic urticaria. Psychosom Med. 1994;56(1):36-40.

8. Fortune DG, Richards HL, Main CJ, Griffiths CEM. Pathological worrying, illness perceptions and disease severity in patients with psoriasis. Br J Health Psychol. 2000;5:71-82.

9. Gupta MA, Schork NJ, Gupta AK, Ellis CN. Alcohol intake and treatment responsiveness of psoriasis: a prospective study. J Am Acad Dermatol. 1993;28(5 Pt 1):730-2.

10. Ginsburg IH, Link BG. Feelings of stigmatization in patients with psoriasis. J Am Acad Dermatol. 1989;20:53-63.

11. Sampogna F, Picardi A, Melchi C, Pasquini P, Abeni D. Prevalence of psychiatric morbidity in patients with psoriasis. Dermatol Psychosom. 2003;4:103-22.

12. Kossakowska NM, Ciescinska C, Jaszewska CJ, Placek WJ. Control of negative emotions and its implication for illness perception among psoriasis and vitiligo patients. JEADV. 2010;24(4):429-33.

13. Gupta MA, Gupta AK, Watteel GN. Early onset $(<40$ years age) psoriasis is comorbid with greater psychopathology than late onset psoriasis: a study of 137 patients. Acta Derm Venereol (Stockh). 1996;76:464-6.

14. Rapp SR, Feldman SR, Exum ML, Fleischer AB, Reboussin DM. Psoriasis causes as much disability as other major medical diseases. J Am Acad Dermatol. 1999;41:401-7.

15. Fouéré S, Adjadj L, Pawin H. How patients experience psoriasis: results from a European survey. JEADV. 2005;19(3):2-6.

16. Kimball AB, Jacobson $\mathrm{C}$, Weiss S, Vreeland MG, Wu Y. The psychosocial burden of psoriasis. Am J Clin Dermatol. 2005;6 (6):383-92.
17. Mukhtar R, Choi J, Koo JY. Quality of life issues in psoriasis. Dermatol Clin. 2004;22:389-95.

18. Meyer N, Paul C, Feneron D, Bardoulat I, Thiriet C, Camara C, et al. Psoriasis: an epidemiological evaluation of disease burden in 590 patients. JEADV. 2010;24:1075-82.

19. Finlay AY. Psoriasis from the patient's point of view. Arch Dermatol. 2001;137:352-3.

20. Krueger GG, Feldman SR, Camisa C, Duvic M, Elder JT, Gottlieb $\mathrm{AB}$, et al. Two considerations for patients with psoriasis and their clinicians: What defines mild, moderate, and severe psoriasis? What constitutes a clinically significant improvement when treating psoriasis? J Am Acad Dermatol. 2000;43(2 pt 1):281-5.

21. Schmid-Ott G, Burchard R, Niederauer HH, Lamprecht F, Künsebeck HW. Stigmatization experience and the quality of life patients with psoriasis and atopic dermatitis. Hautarzt. 2003;54:852-7.

22. Cash TF, Grant J. Cognitive-behavioral treatment of body-image disturbances. In: Van Hasselt V, Hersen M, editors. Sourcebook of psychological treatment manuals for adult disorders. New York: Plenum Press; 1996. p. 567-614.

23. Walker C, Papadopoulos L. Psychodermatology: The psychological impact of skin disorders. Cambridge: Cambridge University Press; 2005.

24. Frangos JE, Kimball AB. Divorce/marriage ratio in patients with psoriasis compared to patients with other chronic medical conditions. J Invest Dermatol. 2008;128 Suppl 1:S87.

25. Koo J. Population based epidemiologic study of psoriasis with emphasis on quality of life assessment. Psychodermatology. 1996;14(3):485-96.

26. Schwartz L, Slater MS. The impact of chronic pain on the spouse: clinical and research implications. Holistic Nurs Pract. 1991;6:9-16.

27. Richards HL, Chong SLP, Mason DL, Griffiths CEM. The impact of psoriasis on healthy partners patients with psoriasis. Br J Dermatol. 2002;147(62):40.

28. Gupta MA, Gupta AK. Psoriasis and sex: a study of moderately to severely affected patients. Int J Dermatol. 1997;36:359-62.

29. Sampogna F, Gisondi P, Tabolli S, Abeni D. Impairment of sexual life in patients with psoriasis. Dermatology. 2007;214:144-50.

30. Rolland JS. Toward a psychosocial typology of chronic and life threatening illness. Fam Syst Med. 1984;2(3):245-62.

31. Jerant AF, Von Friederichs-Fitzwater MM, Moore M. Patients' perceived barriers to active self-management of chronic conditions. Patient Educ Couns. 2005;57:300-7.

32. Kellet S. Shame-focused acne: a biopsychosocial conceptualisation and treatment rationale. In: Gilbert P, Miles J, editors. Body shame: conceptualisation, research and treatment. East Sussex: Brunner-Routledge; 2002. p. 135-54.

33. Bradley C. Translation of questionnaires for use in different languages and cultures. In: Bradley C, editor. Handbook of psychology and diabetes. A guide to psychological measurement in diabetes research and practice. London: Harwood Academic; 1996.

34. Finlay AY, Kelly SE. Psoriasis — an index of disability. Scott Med J. 1985;30:266

35. Finlay AY, Kelly SE. Psoriasis - an index of disability. Clin Exp Dermatol. 1987;198(12):8-11.

36. Finlay AY, Khan GK, Luscombe DK, Salek MS. Validation of sickness impact profile and psoriasis disability index in psoriasis. Br J Dermatol. 1990;123:751-6.

37. Kent G, Al-Abadie M. The Psoriasis Disability Index-further analyses. Clin Exp Dermatol. 1993;18:414-6.

38. Pereira MG, Brito L. Psoriasis Disability Index-research version. Braga: University of Minho; 2008.

39. Spanier GB. Measuring dyadic adjustment: new scales for assessing the quality of marriage and similar dyads. J Marriage Fam. 1976;38:15-28.

40. Spanier GB. Improve, refine, recast, expand, clarify-don't abandon. J Marriage Fam. 1985;47:1073-4. 
41. Busby DM, Christensen C, Crabe DR, Larson JH. A revision of the dyadic adjustment scale for use with distresse and non distressed couples: construct hierarchy and multidimensional scales. J Marital Fam. 1995;21(3):289-308.

42. Pereira MG. Escala Revista de Ajustamento Diádico (RDAS). Research version. Braga: University of Minho; 2003.

43. Hopwood P, Fletcher I, Lee A, Al Ghazal S. A body image scale for use with cancer patients. Eur J Cancer. 2001;37:189-97.

44. Cotrim H, Pereira MG. Imagem Corporal, Morbilidade Psicológica e Qualidade de Vida em Doentes com Cancro Colorectal: Estudos das Características Psicométricas do Body Image Scale. In: Machado C, Almeida L, Guisande M, Gonçalves M, Ramalho V, editors. Livro de Actas da XIII Conferência Internacional Avaliação Psicológica: Formas e Contextos. Braga: University of Minho; 2008. p. 2008.

45. Spielberger CD, Gorush R, Lushene R, Vagg PR, Jacobs GA. Manual for the State-Trait Anxiety Inventory. Palo Alto: Consulting Psychologists Press; 1983.

46. McIntyre L, McIntyre S. State Trait Anxiety Inventory (STAI). Research version. Braga: University of Minho; 1995.

47. Beck A, Steer RA, Brown GK. Manual for the Beck Depression Inventory-II. San Antonio: Psychological Corporation; 1996.

48. Beck AT, Steen RA, Gabrin MG. Psychometric properties of the Beck. Depression Inventory: twenty-five years of evaluation. Clin Psych Rev. 1988;8:77-100.

49. McIntyre M, Araújo-Soares V. Inventário da depressão de Beck: Estudo de validade numa amostra de doente com dor crónica. In: Avaliação Psicológica: Formas e Contextos. Braga: Universidade do Minho; 1999. p. 245-55.

50. Zigmond AS, Snaith RP. The Hospital Anxiety and Depression Scale. Acta Psychiatr Scand. 1983;67(6):361-70.

51. Brito L, Pereira MG. Morbilidade Psicológica e Imagem Corporal em Doentes com Psoriasis Estudo das Características Psicométricas do HADS. In: Machado C, Almeida L, Guisande M, Gonçalves M, Ramalho V, editors. Livro de Actas da XIII Conferência Internacional Avaliação Psicológica: Formas e Contextos. Braga: University of Minho; 2008.

52. McCubbin HI, Larsen AS, Olson DH. F-COPES: Family crisis oriented personal evaluation scales. In: McCubbin HI, Thompson HI, editors. Family assessment inventories for research and practice. 2nd ed. Madison: University of Wisconsin-Madison; 1991. p. 203-16.

53. Mendes F, Relvas AP, Lourenco, MC, et al. Family relationships and primary prevention of drug use on early adolescence. Valencia: IREFREA, European Commission; 1999.

54. Scharloo M, Kaptein AA, Weinman J, Bergman W, Vermeer BJ, Rooijmans HGM. Patient's illness perceptions and coping as predictors of functional status in psoriasis: a 1 year follow-up. Br J Dermatol. 2000;142:899-907.

55. Devrimci-Ozguven H, Kundakci TN, Kumbasar H, Boyvat A. The depression, anxiety, life satisfaction and affective expression levels in psoriasis patients. JEADV. 2000;14:267-71.

56. Youn JI, Park BS, Kim SD, Suh DH. Characterization of early and late onset psoriasis in the Korean population. J Dermatol. 1999;26:647-52.

57. Northouse LL, Mood D, Templin T, Mellon S, George T. Couples' patterns of adjustment to colon cancer. Soc Sci Med. 2000;50(2):271-84.

58. Basra MKA, Finlay AY. The family impact of skin diseases: the Greater Patient concept. Br J Dermatol. 2007;156(5):929-37.

59. Eghlileb AM, Davies EEG, Finlay AY. Psoriasis has a major secondary impact on the lives of family members and partners. $\mathrm{Br}$ J Dermatol. 2007;156(6):1245-50.

60. Pistrang N, Barker C, Rutter C. Social support as conversation: analysing breast cancer patient's interactions with their partners. Soc Sci Med. 1997;45(5):773-82.

61. D'Ardenne P. The couple sharing long-term illness. Sex Relationsh Ther. 2004;19(3):291-308.

62. Rosenstrauch P. The effects of relationship-focused coping on inflammatory bowel disease. Dissertation International: Section B: The Sciences and Engineering 2005; vol. 66.

63. Coyne JC, Smith DAF. Couples coping with myocardial infarction: in a contextual perspective on wive's distress. J Pers Soc Psychol. 1991;61:404-12.

64. Duarte S. Pereira MG. (in preparation). Predictors and moderators of quality of life in patients with systemic lupus erythematosus.

65. Tagkalakis P, Demiri E. A fear avoidance model in facial burn body image disturbance. Ann Burn Fire Dis. 2009;22:203-7.

66. Gordon PA, Perrone KM. When spouses become caregivers: counseling implications for younger couples. J Rehab. 2004;70 (2):27-32.

67. Lyons RF, Sullivan MJL, Ritvo PG, Coyne JC. Relationships in chronic illness and disability. Thousand Oaks: Sage; 1995.

68. Rodrigue JR, Park TL. General and illness-specific adjustment to cancer: relationship to dyadic status and dyadic quality. J Psychosom Res. 1996;40(1):29-36.

69. Segrin C, Badger T, Dorros SM, Meek P, Lopez AM. Independent anxiety and psychological distress in women with breast cancer and their partners. Psycho-Oncology. 2007;16:634-43.

70. Basto L. Variáveis Psicossociais na Psoríase: Um Estudo com Doentes e seus Parceiros (master thesis). Braga: University of Minho; 2008.

71. Cutrona CE. Social support as a determinant of marital quality: the interplay of negative and supportive behaviors. In: Pierce GR, Sarason BR, Sarason IG, editors. Handbook of social support and the family. New York: Plenum; 1996. p. 173-94. 